\title{
ACUTE SOCCER INJURIES IN FINLAND IN 1980
}

\author{
J. SANDELIN, MD, S. SANTAVIRTA, MD and O. KIVILUOTO, MD
}

Division of Orthopaedic Surgery and Traumatology, Surgical Hospital, University Central Hospital, Helsinki, Finland

\section{ABSTRACT}

The present investigation analyses all the acute soccer injuries recorded in Finland during one year (1980). The mean follow-up time was 18 months. The calculated yearly injury incidence was $5.8 \%$. No significant difference in the injury incidences between the two sexes could be detected. A major part, $64 \%$ of the injuries were located in the lower extremities. Fractures and dislocations accounted for $11 \%$ of all injuries. One quarter of the injuries were classified as mild, causing a playing disability shorter than a week. Most injuries occurred through physical contact with another player $(p<0.001)$. The calculated median time of absence from practice after injury was 4 weeks.

Key words: Sports injuries, Soccer.

\section{INTRODUCTION}

Soccer is generally considered to be the most popular game in the world, with more than $\mathbf{4 0}$ million registered players (FIFA 1982). Moreover, it has been said to be the fastest growing team sport, even in the United States (Sullivan et al, 1980; Shama, 1976). Although soccer is an ideal sport in many respects, it has always been associated with a relatively high rate of injury (Ekstrand, 1982; McMaster and Maartens, 1978). Many epidemiological studies have outlined the features and injury rates in soccer (Biener and Fasler, 1978; Ekstrand, 1982; Rooas and Nilsson, 1979; Peterson and Renström 1908; Smodlaka, 1979; McMaster and Maartens, 1978) and Franke in 1980 suggested that of all sports injuries in Europe, $50 \%$ occur in soccer alone.

In Finland soccer is played by some 70,000 players in over 4,000 teams. The total number of matches each year averages 78,000 which equals some $\mathbf{2 0 0}$ matches each day (National Soccer Association, 1980). Earlier researchers in Finland have analysed the late sequelae of lower extremity soccer injuries (Solonen, 1966) and the features of popular work-place soccer injuries (Orava and Puranen, 1975). The present study was planned to review the rate and features of acute soccer injuries in Finland.

\section{MATERIAL AND METHODS}

All soccer players in Finland participating in games arranged by the National Soccer Association have obligatory insurance cover valid for one year. The premium fee is low and covers the costs of those injuries occurring in matches and during training. Exertion injuries are not taken into account. Because of this arrangement, which is similar to those in the other Nordic Countries, most injuries, especially all major injuries that require medical attention are thus reported and registered. The material of the present study consists of all the acute socce injuries reported to the insurance company during one year (1980). The insurance files were analysed and to complement the analyses a questionnaire on a randomised basis was sent to every fourth of the injured, the response rate being $77 \%$. From the questionnaire more detailed information concerning the injury as well as the skill and experience of the injured soccer player was obtained. Overuse injuries were excluded from this study and all injuries were classified according to their severity and treatment and categorised as mild, moderate and severe. A mild injury was any injury that required up to one week of missed practice. A moderate injury caused the player to miss one to four weeks of practice, while a severe injury disabled the player for more than four weeks. The major part of the injured, $96 \%$, were men, and $4 \%$ women. The calculated mean age of the men was 26 years 110 58) while that of the women was 23 years (13-33). The mean follow-up time was 18 months. In performing the statistical analyses the chisquare test was used.

Correspondence to:

Jerker Sandelin, MD

Division of Orthopaedic Surgery and Traumatology,

University Central Hospital,

Kasarmikatu 11-13,

Helsinki 13,

Finland

\section{RESULTS}

During the one-year period 2,072 soccer injuries demanding medical care were recorded. The total number of registered soccer players participating in the different leagues was 35,500 and the calculated injury incidence thus being $5.8 \%$. During the same time period 1,761 teams participated in different official series and the injury rate per team hence was 1.2.

We found significantly more injuries occurring in the two top divisions compared to the lower ones ( $<<0.001)$ during the reviewed year and two peaks during the seasons when significantly more injuries happened ( $p<0.001$ ) (Fig. 1). The distribution of injuries in women and men to different parts of the body appears in Table I. No significant differences between the two sexes could be detected. A major part of the injuries $(64 \%)$ were located in the lower extremities, followed by injuries to the upper extremities (14\%). In $13 \%$ the injury involved the head and neck region and least injuries was recorded in the trunk $(9 \%)$

\section{MONTHLY DISTRIBUTION OF SOCCER INJURIES IN FINLAND (1980)}

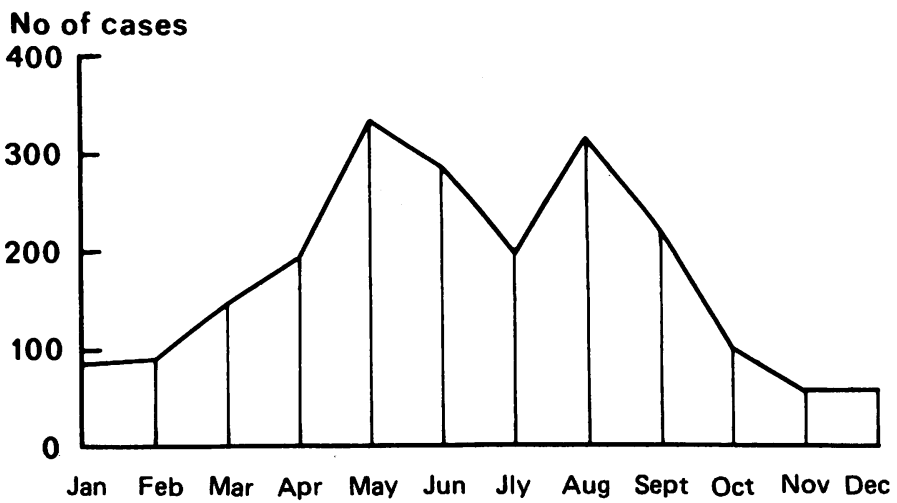

Fig. 1

TABLE I

Localisation of injury $(N=2072)$

$\begin{array}{lccccc}\text { Sex } & \begin{array}{c}\text { Head and } \\ \text { neck }\end{array} & \text { Trunk } & \begin{array}{c}\text { Localisation (\%) } \\ \text { Upper } \\ \text { extremity }\end{array} & \begin{array}{c}\text { Lower } \\ \text { extremity }\end{array} & \begin{array}{c}\text { Total } \\ \begin{array}{l}\text { Female } \\ N=83\end{array}\end{array} \\ \begin{array}{l}\text { Male } \\ N=1989\end{array} & 14 & 7 & 16 & 68 & 100 \\ \begin{array}{l}\text { Total } \\ N=2072\end{array} & 13 & 9 & 13 & 64 & 100 \\ & & 9 & 14 & 64 & 100\end{array}$

The distribution of types of injury at various body sites is shown in Table II. Strains and sprains together with contusions formed $88 \%$ of all injuries. Fractures and dislocations accounted for $11 \%$ of the injuries.

Of the injuries to the head and neck area, $40 \%$ consisted of dental injuries. Concussion was the case in $7 \%$ and ocular injuries were found 
TABLE II

Type of injury at different body sites $(N=2072)$

\begin{tabular}{|c|c|c|c|c|c|}
\hline \multicolumn{6}{|c|}{$\begin{array}{c}\text { Type of Injury } \\
(\%)\end{array}$} \\
\hline Location & $\begin{array}{l}\text { Strain and } \\
\text { sprain }\end{array}$ & Contusion & $\begin{array}{l}\text { Fracture and } \\
\text { dislocation }\end{array}$ & Other & Total \\
\hline $\begin{array}{l}\text { Head and } \\
\text { Neck }\end{array}$ & - & 84 & 8 & 8 & 100 \\
\hline Trunk & 50 & 42 & 8 & - & 100 \\
\hline $\begin{array}{l}\text { Upper } \\
\text { extremity }\end{array}$ & 24 & 38 & 38 & - & 100 \\
\hline $\begin{array}{l}\text { Lower } \\
\text { extremity }\end{array}$ & 58 & 34 & 7 & 1 & 100 \\
\hline Total & $\begin{array}{c}45 \\
(N=939)\end{array}$ & $\begin{array}{c}42 \\
(N=874)\end{array}$ & $\begin{array}{c}11 \\
(\mathrm{~N}=228)\end{array}$ & $\left(N^{2}=30\right)$ & $\begin{array}{c}100 \\
(N=2072)\end{array}$ \\
\hline
\end{tabular}

in $6 \%$ of all injuries to this area. Fractures in this area were rare, the total number of fractures to the facial bones and skull accounting for $9 \%$ of all fractures.

Among the injuries to the upper extremities a remarkable $38 \%$ consisted of fractures and dislocations. However, a closer analysis revealed that over two thirds of these injuries were located in the hand or fingers, and $16 \%$ were located to the lower arm, these being mostly distal radial fractures. Complicated fractures of the cubital or upper arm occurred in only a few cases in this series.

Most of the injuries to the trunk were cuts and bruises or strains of the soft tissues. Fracture in this region consisted mainly of fractures to the ribs, which accounted for $5 \%$ of all fractures, and fractures of the clavicle, which were seen in an equal amount.

Of the injuries to the lower extremities over half $(58 \%)$ were strains and sprains, followed in statistics by cuts and bruises (34\%). Fracture and dislocations accounted for $7 \%$ of all injuries to the lower extremities. Of all fractures, however, those located in the lower leg were as common as those located in the hands and fingers (Table III). These notorious fractures usually disables the player from playing soccer for the whole season and lead to high numbers of days lost from work and furthermore to high insurance payments. Fractures of the ankle region accounted for $10 \%$ of all fractures and were as a rule treated operatively.

TABLE III

Distribution of fractures $(N=207)$

$\begin{array}{llr}\text { Localisation } & \text { N } & \% \\ \text { Hand and wrist } & 39 & 19 \\ \text { Lower leg } & 37 & 18 \\ \text { Ankle } & 21 & 10 \\ \text { Forearm } & 15 & 7 \\ \text { Finger } & 14 & 7 \\ \text { Toe } & 13 & 6 \\ \text { Clavicle } & 11 & 5 \\ \text { Rib } & 10 & 5 \\ \text { Other } & 47 & 23 \\ \text { Total } & 207 & 100\end{array}$

When looking at the location of the injuries to the lower extremity $34 \%$ were located in the knee, another vulnerable site being the ankle region, accounting for $31 \%$ of all injuries to the lower extremities (Table IV). A more detailed analysis of the knee injuries revealed that most common were injuries to the ligamentous structures $(40 \%)$ followed by lesions to the meniscal structures of the knee, which accounted for $31 \%$ of all injuries to this area (Table V).

TABLE IV

Distribution of soccer injuries in lower extremity $(N=1334)$

$\begin{array}{lcc}\text { Location } & N & \% \\ \text { Knee } & 460 & 34 \\ \text { Ankle } & 412 & 31 \\ \text { Hip } & 179 & 13 \\ \text { Foot } & 146 & 11 \\ \text { Lower leg } & 127 & 10 \\ \text { Other } & 10 & 1 \\ \text { Total } & 1334 & 100\end{array}$

TABLE V

Soccer injuries in the knee joint $(N=460)$

$\begin{array}{lrr} & \text { N } & \% \\ \text { Ligamentous injuries } & 185 & 40 \\ \text { Meniscal injuries } & 141 & 31 \\ \text { Contusions } & 125 & 27 \\ \text { Fractures and dislocations } & 9 & 2 \\ \text { Total } & 460 & 100\end{array}$

One quarter of the injuries could be classified as mild, causing the player to miss up to one week's practice. Moderate injuries were found in $27 \%$ and in $48 \%$ the injury was classified as severe.

Playing position on the soccer field did not produce any difference in the spread of the injuries. Goalkeepers, defenders, mid-field players and forwards all showed a fairly equal injury incidence that statistically showed no significant difference. In this series, goalkeepers seemed to be involved in slightly less severe injuries than other players. This difference was not statistically significant. More of the injuries occurred during official games $(p<0.001)$ than during practice, and when both halves of the game were divided into two, a slight tendency for more injuries to occur in the third quarter was seen. This difference could not, however, be statistically proven (Table VI).

TABLE VI

Injuries during different periods of soccer game ( $N=2072$ )

\begin{tabular}{lr} 
Situation & $\%$ \\
Game & 71 \\
- First quarter & $(31 \%)$ \\
- Second quarter & $(32 \%)$ \\
- Third quarter & $(37 \%)$ \\
- Fourth quarter & \multicolumn{2}{c}{$(20 \%)$} \\
Practice & 23 \\
Warm-up & 4 \\
Other & 2 \\
Total & 100
\end{tabular}

It is significant that most injuries occurred through physical contact with another player, in $52 \%$ (p $<0.001$ ). Non-contact injuries occurred during running and dribbling accounted for $29 \%$, and in $5 \%$ the injury was caused by a direct blow from the ball.

According to the present analysis the pitch surface did not influence the injury frequency or pattern. We found the injury rate and profile to be the same on sand and grass. The median of the sick-leave after a sustained injury was two weeks and the calculated median of the absence from practice was four weeks after a soccer injury.

\section{DISCUSSION}

Soccer is an ideal, inexpensive sport for youths, providing good exercise that can be continued into adult life. Furthermore, soccer is a good outlet for aggression (Sullivan et al, 1980). However, a high incidence of injury in soccer has been noted by many authors (Biener and Fasler, 1978; Ekstrand, 1982; Jelinek, 1971; Orava and Puranen, 1975; Rooas and Nilsson, 1979). According to Franke, over half of all sports injuries and up to $10 \%$ of those sports injuries requiring hospital treatment are caused by soccer alone (Franke, 1980). However, some investigators from the United States have calculated the risk of sustaining an injury in American football to be five times higher (Prichett, 1981; Shaffer, 1973). The present investigation showed an annual injury rate of $5.8 \%$ among registered soccer players. In different studies the injury incidence in soccer has varied somewhat, Groh and Groh reporting in Germany in 1975 a somewhat higher number of $10.2 \%$. On the other hand, Sullivan et al (1980) from the United States reported an injury incidence of $2.6 \%$ and Prichett (1981) an incidence of 4.1\% among high school soccer players.

In the present study more injuries were seen in the two top divisions, and corresponding results were reported by Rooas and Nilsson (1979) in Norway. Peterson and Renström (1980) on the contrary, in a study describing soccer injuries in 
Sweden could not find any difference in the injury incidence between the players in different divisions. However, it is noteworthy that players in the top divisions spend more time practicing and playing games than players in the lower divisions. Therefore many investigators when calculating the injury risk in sports stress the importance of the exposure factor when the injury incidence is reported (Canale et al, 1981; Ekstrand, 1982; Sullivan et al, 1980). Owing to the nature of this study, the exposure factor and its relationship to the injury rate could not be calculated, though the number of matches and practice sessions are greater in the top division.

A number of studies analysing soccer injuries have shown that a major part of the injuries are located in the lower extremities (Orava and Puranen, 1975; Pritchett, 1981; Peterson and Renström, 1980; Rooas and Nilsson, 1979; Thomas and Reilly, 1975). In our series, $64 \%$ of all injuries were located in the lower extremities, this being in accordance with most other investigations on soccer injuries. In Ekstrand's recent study (1982) acute and exertion injuries were not analysed separately and thus he reports an unusually high number of $88 \%$ of all injuries being located in the lower extremities.

In soccer the head is frequently used for contact with the ball and thus when two players go for the ball injuries to the head and neck area are prone to happen. In our series, $13 \%$ of the injuries were located in the head and neck, this figure being in accordance with other studies of soccer injuries (Prichett, 1981; Canale et al, 1981; Peterson and Renström, 1980). Of all the publications we are familiar with, only Rooas and Nilsson in a survey of major soccer injuries in Norway in 1979 report a higher figure, $22 \%$ being head and neck injuries. The present series did not include serious injuries to the head and neck or severe intracranial trauma. No fracture-luxation of the spine was found in these series, this injury being frequently described in contact sports and often leading to disastrous neurological losses (McCoy et al, 1984; Canale et al, 1981).

We could not detect any preponderance of head and neck injuries occurring more often among goalkeepers and defenders as pointed out by Peterson and Renström (1980) and others (Prichett, 1981; Wilkinson, 1978). The injury pattern in our study was in accordance with other studies concerning injuries, strains and sprains being the predominant injuries followed by cuts and bruises (Wilkinson, 1978; Canale et al, 1980; Peterson and Renström, 1980; Ekstrand, 1982). Fractures and luxations formed $10 \%$ of the injuries and the same number is reported in other studies. Only Rooas and Nilsson reports a high number of $42 \%(1979)$. The spread of fractures at different parts of the body was, however, similar to ours.

The present investigation reflects the extreme vulnerability of the knee joint in soccer players. Of all injuries, the knee joint was involved in $22 \%$ of cases and out of all injuries to the lower extremities the knee accounted for over one third.

Most often injuries to the knee joint involved the ligaments followed by injuries to the menisci. Although ligamentous injuries to the knee are considered serious because of the great risk of reinjury and late sequelae leading to chronic instability (Ekstrand, 1982; Müller, 1983), most investigators seem to agree that soccer is first and foremost a hazard to the menisci (Biener and Fasler, 1978; Rooas and Andersson, 1977; SonneHolm et al, 1977). A blow on the knee while weight-bearing is more likely to cause damage to the menisci than on the ligamentous structures, which on the contrary are usually more prone to injury in skiing, here the injury occurring by rotation of the non-weight-bearing knee joint (Johnsson et al, 1980; Edlund et al, 1980). Another vulnerable site was the ankle where $29 \%$ of all injuries to the lower extremities in soccer are located. Of the injuries to the ankle, $75 \%$ were distorsions mostly involving the lateral ligamentous structures. This injury is, according to many investigators, the most common sports injury (Garrick, 1977; Muckle, 1978; Sullivan et al, 1980; Wilkinson, 1978). In a recent prospective study of soccer injuries and their prevention Ekstrand (1982) concluded that $73 \%$ of the acutely sprained ankles involved ankles that had been previously injured. Ekstrand further concluded agreeing with Bender's earlier statement that most of these injuries were due to premature return to playing and training after injury (Ekstrand, 1982; Bender et al, 1964). We found only $5 \%$ of all injuries to the ankle to be fractures this being in clear contrast with the Rooas and Nilsson study (1979) where fractures were found to occur more often than sprains. However, what was meant by sprain was not clearly defined in their study.

It is interesting, that from this study it appears that the injuries were evenly distributed throughout the members of the team, this being in accordance with a similar study from Sweden (Peterson and Renström, 1980). However, some investigators have shown a higher susceptibility to injuries among goalkeepers and have thus stressed more intensive supervision by the referee in and around the goal area (Sullivan et al, 1980; Wilkinson, 1978).

Our analysis is based on those soccer injuries which were reported to the football association insurance company Therefore minor injuries which did not demand a physician's treatment and did not lead to sick leave were excluded from the analysis. This partly explains the relatively high number of severe injuries in this series when compared to other reports concerning soccer injuries (Ekstrand, 1982; Peterson and Renström, 1980; Canale, 1981). However, this analysis does cover the major soccer injuries in Finland.

Canale et al (1981) in a study of football injuries from the United States found unexpectedly fewer injuries to occur in a losing team. In this study team success did not influence the occurrence of injuries in a team, there being no significant difference between losing and winning teams. A number of soccer injuries can be avoided by introducing appropriate safety equipment including shin pads for lower leg protection with anatomic fitting. By introducing a prophylactic programme against injuries in soccer Ekstrand was able to lower the injury rate by a considerable $75 \%$ during one year (Ekstrand, 1982). The prophylactic programme included supervision by the team doctor and an adequate rehabilitation programme after injury. However, we feel that the referee's role as the game supervisor is most important and violence should not be tolerated under any circumstances in soccer.

\section{References}

Bender, J. A., Pierson, J. K., Kaplan, H. D. and Johnson, A. J., 1964 "Factors affecting the occurrence of knee injuries". JAMR 18: 130-134.

Biener, K. and Fasler, K., 1978. Sportunfälle. Hans Huber Verlag, Bern.

Canale, T. S., Cantler, E. D., Sisk, T. D. and Freeman, B. L., 1981 "A chronicle of injuries of an American intercollegiate football team". Am.J.Sports Med. 9: 384-389.

Edlund, G., Gedda, P. and Hemborg, A., 1980 "Knee injuries in skiing". Am.J.Sports Med. 8: 411-413.

Ekstrand, J., 1982 "Soccer injuries and their prevention". Academic dissertation. Linköping University.

FIFA 1982. Statistics on the 150 affiliated national associations of FIFA.

Franke, K., 1980. Traumatologie des Sports. Georg Thieme Verlag, Stuttgart.

Garrick, J. K., 1977 "The frequency of injury mechanism of injury and epidemiology of ankle sprains". Am.J.Sports Med. 5: 241-242.

Groh, $H$. and Groh, P., 1975. Sportverlezungen und Sportschäden. Luitpold-Werk, Munchen.

Jelinek, R., 1971 "Verlezungen beim Fussballsport". Österr.J.Sport med. 1 : $5-15$.

Johnson, R. J., Ellinger, C. F., Campbell, B. S. and Pope, M. H., 1980 "Trends in skiing injuries". "Am.J.Sports Med. 8: 106-113.

McCoy, G. F., Piggott, J., Macafee, A. L. and Adair, L., 1984 "Injuries of the cervical spine in schoolboy Rugby football". J.Bone Join Surg. 66B: 500-503. 
McMaster, W and Maartens, W. 1978 "Injuries in soccer". Am.J. Sports Med. 6: 354-357.

Muckle, P. S., 1978 "Injuries in sport". John Wright \& Sons Ltd., Bristol.

Müller, W 1983. The Knee, Springer Verlag, Berlin.

National Soccer Association of Finland. Bulletin. 1980.

Orava, S. and Puranen, J., 1975 "Injuries resulting from work-place football". Duodecim. 91: 714-718.

Peterson, L. and Renström, P., 1980. "Sport medicine". Läkartidningen. 77: 3613-3630.

Prichett, J. W., 1981 "Cost of high school soccer injuries". Am.J.Sports Med. 9: 64-66.

Rooas, A. and Andersson, G., 1977 "Knee injury rate in football players and in the population at large". Acta Orthop.Scand. 48: 223.

Rooas, A. and Nilsson, S., 1979 "Major injuries in Norwegian football". Brit.J.Sports Med. 13: 3-5.

Shaffer, T. E., 1973 "The adolescent athlete". Ped.Clin.North Am. 20: $837-842$.
Shama, D. 1976 "Soccer blends skill, stamina, simplicity". Physician Sportsmed. 4: 115-120.

Smodlaka, V. N., 1979 "Rehabilitation of injured soccer players". Physician Sportsmed. 7: 57-61.

Solonen, K. 19766 "The joints of the lower extremities of football players". Ann.Chir.et Gyn. 55: 176-180.

Sonne-Holm, S., Ahn, N. C. and Fledelius, I., 1977 "Meniscectomy. A 10-year follow-up of 150 athletes". Acta Orthop.Scand. 48: 223. Sullivan, J. A., Gross, R. H., Grana, W. A. and Carcia-Moral, C. A., 1980 "Evaluation of injuries in youth soccer". Am.J.Sports Med. 8: 325-327.

Thomas, V. and Reilly, T., 1975 "The relationship between anxiety variables and injuries in top class soccer". Proceedings of FEPSAC Conference 213-222, Edinburgh.

Wilkinson, W. H. 1978 "A practical view of soccer injuries". Brit.J. Sports Med. 12: 43-45.

\section{BOOK REVIEW}

Title:

Authors:

Publishers:

\section{PRINCIPLES OF SPORTS MEDICINE}

Scott, Nisonson et al

Williams and Wilkins, London

Price: $£ 60 \quad 433$ pages

Index

ISBN 0-683-07615-9

The title of this book is a misnomer. Although some of the principles of sports medicine are dealt with in considerable depth, the vast majority of the book deals specifically with trauma, and there are many areas of sports medicine which are omitted. It therefore cannot be regarded as a basic textbook but rather an exposition of sports traumatology with a little additional information on the cardiovascular system, the neuromuscular system, nutrition and drugs.

The book as a whole is frankly directed to the American market with much directly orientated to specific American sports, e.g. football. The pattern of injury, therefore, and the degree of emphasis laid on different types varies from what is common in the United Kingdom, and there are some remarkable omissions. Is it really the case that Achilles tendon pain does not afflict Americans?! And why no reference to jumper's knee - surely a particularly American problem?!

Much of the text is taken up with the description of orthodox traumatology and there are some excellent illustrations including clinical photographs, models, operation photographs and radiographs - but the standard of other illustrations is to say the least poor, and in some sections radiographs are almost indecipherable.

A book of this magnitude should offer as one of its attractions, its bibliography. Again, here the bibliography is patchy. The references tend to come straight off one or other of the data bank computers (or so it seems) and one is concerned as to whether some of the authors have even read, let alone understood, some of the papers they quote.

It would be invidious to single out individual chapters for criticism as to single any out for specific praise. The book is patchy in content and in presentation for so lavish a publication. It will be of value to the discerning reader because there are many good things in it but it cannot be recommended as a prime source as there are many more comprehensive texts, both in the United States of America as well as in the United Kingdom, more roundly presenting the principles of sports medicine.

J. G. P. Williams

\section{BOOK REVIEW}

Title: CLINICS IN SPORTS MEDICINE - INJURIES TO DANCERS

Editor:

Publishers: $\quad$ W. B. Saunders Company, 1 St. Anne's Road, Eastbourne, E. Sussex, November 1983 Price: $£ 17.00 \quad 656$ pages Hardback

This 656 page hardback book is one of a series of clinics and is numbered Volume 2 No. 3 and was published in November 1983. Edited by G. James Sammarco, MD its contributors are principally from Ohio and Massachusetts, USA with a chapter by Dr. Ronald Quirk, MD, FRCS, FRACS Australia and Mr. Justin Howse, MD, FRCS, Orthopaedic Consultant Royal Ballet School.

It contains a mass of information for all those who are concerned with the care of patients who indulge in heavy or repeated physical activity and especially for those that have an interest in classical ballet and other dance forms.

It is well indexed, well illustrated - with both line drawings, radio and photographics.

I enjoyed reading this and would recommend it. 